\title{
Life-Span Perspective of Personality in Dementia
}

\author{
Ann M. Kolanowski, Ann L. Whall
}

Purpose: To propose an alternative view of personality change in dementia by presenting existing evidence for the continuity of personality.

Significance: As the population continues to age, dementing illnesses will account for a greater proportion of morbidity and mortality; the care of these people will have a significant effect on the health care system.

Organizing Framework: Life-span perspective of personality continuity.

Scope, Method: Review of current literature on personality in dementia using Medline, 1980 -1994; CINAHL, 1990-1994; and Psych Lit., 1980-1994.

Findings: Although there are systematic shifts in personality with dementia, individuals tend to maintain their unique pattern of premorbid personality traits.

Conclusions: The personalities of dementia patients seem to reflect adaptive patterns that served them in the past.

Implications: Use of a life-span perspective can enhance individualized care for demented patients and advance theory development.

imace: Journal of Nursing Scholarship, 1996; 28(4), 315-320 . O1996, Sigma Theta Tau International.

[Keywords: dementia; personality; life cycle]

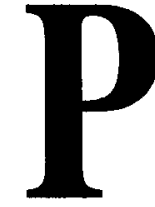
ersonality is the configuration of thoughts, feelings, and behavior that determine a person's unique pattern of adaptation (Millon, 1969). One of the criteria used to diagnose dementia is a change in personality (American Psychiatric Association, Diagnostic and statistical manual of mental disorders, 1994). Behavioral alterations can be a source of great distress and are a frequent cause of institutionalization (Colerick \& George, 1986).

The literature describes behavioral disintegration of dementia as a loss of personal identity. Because Western culture places great worth on individuality, the loss of identity places one at risk of being devalued (Glover, 1988). In nursing homes, anonymity can reinforce stereotypic thinking (Milliard \& Smith, 1981) and may routinize caregiving (Diamond, 1986).

In the past, efforts to explain behaviors in dementia have used two broad approaches. The first, the biomedical approach, characterizes behaviors as discontinuous (Raskind \& Peskind, 1994). In this perspective there is the notion that personalities can be classified into a few specific types as dementia progresses (Bozzola, Gorelick, \& Freels, 1992; Rubin, Morris, \& Berg, 1987). The methods of biomedical science and their focus on commonalities have advanced our knowledge of disease and are appropriate for understanding biophysical changes (Wolfer, 1993). But biomedical science is not concerned with the purpose or meaning of a phenomena (Benner \& Wrubel, 1989). Understanding individual experiences requires interpretation in an appropriate context (Allen, 1985).

A second grouping of perspectives relates personal and environmental characteristics to behavior in dementia (Kahana,
1982; Lawton, 1982; Moos, 1980). These theoretical perspectives have provided a basis for several interventions, but as in biomedical research, investigators have focused on problematic behaviors.

What is lacking is a life-span perspective of dementia that identifies adaptive responses over time and embodies the idea of "knowing the patient" (Jenny \& Logan, 1992).

\section{Development of Personality}

The study of personality has a long history and a number of different perspectives (Field, 1991). "Personologists" emphasize the inner organization of personality and believe that behavior is consistent over time and situations. This view has stimulated work on the heritability of personality traits (Zuckerman, 1991). A second view is that of the situationists or behaviorists who assert the importance of the environment. In this view, behavior is affected by contextual factors and may change depending on the situation. A third perspective is that of the interactionists who

Ann M. Kolanowski, RN, PhD, Zeta Psi, is Professor and Chairperson, Department of Nursing, Wilkes University, Wilkes-Barre, PA. Ann L. Whall, RN, PhD, FAAN, Lambda, Professor, is Associate Director of the Geriatric Center, University of Michigan, Ann Arbor, MI. The authors wish to acknowledge this work was supported by National Institutes of Health T32-NR07074, when Ann Kolanowski was a research fellow at the University of Michigan School of Nursing. Correspondence to Dr.

Kolanowski, 217-219 S. Franklin St., Wilkes-Barre, PA.

Accepted for publication June 8, 1995. 
recognize the reciprocal relationship between a person and situation. Behavioral genetic research has contributed to the development of this perspective by demonstrating the importance of genetic and environmental factors (Carey \& DiLalla, 1994).

The construct of personality has been measured with numerous scales and inventories. In the past 10 years, personality psychologists have come to agree on a fundamental taxonomy of personality traits or dispositions to act known as the five-factor model (Digman, 1990). Developed from analyses of natural languages (John, Angleitner, \& Ostendorf, 1988) and personality inventories (McCrae, 1989), the model consists of five major personality factors: Neuroticism, extraversion, openness, agreeableness, and conscientiousness. Neuroticism is the tendency to experience fear, sadness, embarrassment, anger, guilt, and disgust. Extraversion is the tendency to be sociable, assertive, active, and talkative. Openness includes elements of active imagination, aesthetic sensitivity, attentiveness to inner feelings, preference for variety, intellectual curiosity, and independence of judgment. Agreeableness is characterized by trust, straightforwardness, altruism, and modesty. Conscientiousness refers to traits of competence, order, dutifulness, achievement, striving, and self-discipline (Costa \& McCrae, 1992). The five-factor model has been found useful for assessing the general population as well as those with psychopathology (Watson, Clark, \& Harkness, 1994).

Personality as a developmental phenomena has been explored in a number of longitudinal studies. In general, these studies have demonstrated the stability of personality over time (Conley, 1984; Haan, Millsap, \& Hartka, 1986). Investigations which extend into old age, such as the Baltimore Longitudinal Study on Aging have reported similar results (McCrae \& Costa, 1987). Recently, information about personality in advanced age has been available from Field and Millsap's (1991) follow-up of 74 surviving members of the Berkeley Older Generation Study. Subjects, who ranged in age from 73 to 93 years, were first interviewed in 192829 when they were young adults. The primary finding with respect to personality was of stability; where there was change, each trait followed its own trajectory. The study provides evidence of consistency for satisfaction (self esteem) and intellect (a composite of five indicators of cognitive functioning and openmindedness). Traits which changed were those of agreeableness which increased, and extraversion which declined. The authors suggest that aspects of personality that change in the very old are truly developmental. The decline in extraversion, for example, may represent Neugarten's (1973) idea of greater innerdirectedness. Alternatively, personality changes may provide clues to the effect of the environment on the aging person (Wrightsman, 1988).

\section{Personality in Dementia}

\section{Biomedical Approach}

The biomedical perspective on behavior in dementia emphasizes correlation between problematic behavior and the progression of disease. Petry and colleagues (1988) found personality changes that were quite similar for the majority of their 30 Alzheimer's subjects. Subjects with greater severity of dementia demonstrated a common pattern of increased passivity, coarseness of affect, and decreased spontaneity. In a 4-year longitudinal study of 24 subjects, who initially presented with mild senile dementia of the Alzheimer type (SDAT), it was found that passive and agitated behaviors increased with the severity of dementia, and suspiciousness and self-centered behaviors disappeared at moderate stages of the illness (Rubin, et al. 1987).

Efforts have been made to relate behaviors in dementia to brain-area pathology. Demented patients with frontal lobe damage, are less inhibited, unconcerned, hostile, and restless (Sungaila \& Crockett, 1993). Similarly, deLeon, Portegal, and Gurland (1984) identified a subgroup of Alzheimer's disease (AD) patients who wandered and noted that this group had significantly poorer performance on tests of parietal function. In a recent study of 27 AD patients, Knesper, Giordani, Koeppe, and Kuhl (1994), reported that left-sided metabolic reductions in brain function were associated with anxiety-tension $(r=.33)$, hostility $(r=.52)$ and depression $(r=.46)$.

\section{Person-Environment Approach}

Models from social gerontology have also been used as frameworks for the study of the effect of personal competence and of environmental characteristics on behavior.

Evidence indicates that frail elders are most likely to manifest disturbing behaviors. Positive, but modest relationships, have been demonstrated between disturbing behaviors and impairments in activities of daily living (Cohen-Mansfield, Billig, Lipson, Rosenthal, \& Pawlson, 1990), and cognitive losses (Teri, Larson, \& Reifler, 1988).

Environmental factors have been associated with behavior in dementia. In general, the greater the number of disturbing behaviors by a person, the more his or her social network is characterized by lack of intimacy (Cohen-Mansfield \& Marx, 1992). In intervention studies, environmental factors that seem to support adaptive behavior in demented elders include the behavior of caretakers (Burgener, Jirovec, Murrell, \& Barton, 1992), the knowledge base of caretakers (Evans, Strumpf, Taylor, \& Jacobsen, 1990-92), and the physical environment (Whall, Black, Yankou, \& Groh, 1994).

\section{Life-Span Perspective}

The research described above has provided much information on brain-behavior relations and has helped in identifying aspects of the environment that can be altered to support the dementia patient. However, most of this research was cross-sectional and personality was narrowly defined. A broad, comprehensive perspective is needed to understand how personality changes in dementia and to capture patterns that are continuous with earlier ones.

In interviews with family members of demented patients, Shomaker (1987) found evidence for the continuity of patients' normal behavior patterns. Intense examination of her patients' behaviors revealed the disease caused fragmentation, intensification, and increased frequency in previous, wellestablished behaviors. It was reported that linking current behaviors to those in the past helped family members understand 
what patients were trying to communicate through their behavior.

Several studies of aggressive behaviors in dementia described subjects as those with a prior history of aggression (Ryden, Bossenmaier, \& McLachlan, 1991; Hamel, Pushkar, Andres, Reis, Dastoor, Grauer, \& Bergman, 1990). In one study, abusive residents were described by their significant other as having a history of being controlling, domineering, and erratic (Meddaugh, 1994).

Recent studies of personality change in dementia have added to our understanding by using broad-band instruments for the measurement of personality. Most of these studies have used report of an informant, a method found to be both valid and reliable for measuring personality (Strauss, Pasupathi, \& Chatterjee, 1993).

In work using the NEO Personality Inventory (NEO PI)-a 240-item Likert-type scale that measures five major domains of personality-Chatterjee, Strauss, Smyth, and Whitehouse (1992), asked caregivers of 38 moderately demented patients to rate patients' personality twice. The first time was to describe the subject's premorbid personality, the second to describe the present personality. Significant changes for all five factors were found: The largest changes were decreases in extraversion and conscientiousness, and an increase in neuroticism. The amount of change did not correlate with mental status or duration of illness, suggesting that factors other than disease influence behavior. But while the absolute level of dimensions changed, subjects' rank order within groups remained relatively consistent. There were significant correlations between premorbid and current ratings for neuroticism $(r=.76)$, extraversion $(r=.67)$, openness $(r=.77)$, and agreeableness $(r=.79)$. There was also evidence that premorbid personality traits predisposed patients to psychiatric symptoms in AD. Patients with depressive features were reported as having been more fearful, angry, depressed, or impulsive premorbidly while patients with paranoid delusions were remembered as more hostile.

These findings are strengthened by those of Siegler and colleagues (1991), who asked caregivers of 35 mildly to moderately memory-impaired patients to rate current and premorbid personalities using the NEO PI. Again, this group of subjects was described as significantly more neurotic and as less extraverted, open, and conscientious. For 21 of 23 facets, there were significant correlations between pre- and post-ratings of personality.

Richman (1989) studied personality stability in 46 nursinghome residents who met the criteria for mild dementia on the Mini-Mental Status Exam and Mental Status Questionnaires. These subjects and their primary caregivers rated subjects on their premorbid and present personality. Results of the caregivers' ratings indicated an increase in neuroticism and a decrease in extraversion and conscientiousness. The change in neuroticism and extraversion, however, were not considered clinically significant; when comparing subjects' profiles to normative data, subjects' average scores remained in the "high" range for neuroticism and "low" for extraversion. There was no statistically significant difference in mean scores for openness and agreeableness.
The comparison of family ratings to self-ratings indicated discrepancies in perceptions of the subjects' current personality. Family members perceived subjects as more neurotic, less extraverted, less open, less agreeable, and less conscientious than subjects saw themselves at the time of rating. Subjects believed they were currently more like their former selves. Additionally, subjects' reliability of self-rating $(N=17)$ demonstrated a high degree of consistency from the point of initial assessment to retest 7 to 14 days later ( $r=.76$ for agreeableness to .95 for neuroticism). The conclusion drawn was that mildly demented subjects can give reliable self-reports, a data-collection strategy often overlooked in dementia research.

Taken together, these results indicate that while there are systematic shifts in personality with dementia, people maintain their unique configuration or pattern of personality. There is remarkable consistency in the rank-order of personality traits from pre- to post-morbid periods at least for mild and moderately demented patients. It has been suggested that dementing illnesses interact with premorbid personality, producing changes that give "drama and intensity" to life-long traits (Sadavoy, 1991). Furthermore, patients in the earlier stages of the disease seem to experience themselves as they were in their past. At the very least, these data suggest that there may be a degree of both external and internal continuity as described by Atchley (1989). The personality of a demented person seems to reflect adaptive patterns that served them in the past. Researchers and practitioners who take into account a patient's premorbid personality may be in a better position to understand and respond to seemingly new behaviors.

\section{Personality and Life Events}

A person becomes defined in the course of his or her life and a number of studies give evidence of a relationship between life events and behavior in dementia. Snyder, Rupprecht, Pyrek, Brekhus, and Moss (1978) report that a chart audit of social history records for eight institutionalized wanderers indicated that wandering was related to life-long patterns of coping and previous work roles. Monsour and Robb (1982) also explored the notion that the tendency to wander is consistent with lifelong psychosocial patterns. It was determined that: (a) before their illnesses, wanderers engaged in a higher level of social and leisure activities than did non-wanderers; (b) wanderers experienced more stressful life events than did non-wanderers; (c) wanderers showed a motoric reaction to stress in their earlier years; and (d) wanderers demonstrated more motoric behavioral styles in their earlier years.

The relation of agitated behavior to prior life events was explored in a study of 408 nursing-home residents (CohenMansfield \& Marx, 1989). They found that residents who engaged in the more physically non-aggressive behaviors of pacing and wandering were more likely to have experienced separation from a spouse, a life-threatening experience, financial problems, or immigration. Those who displayed aggressive behavior were more likely to have experienced financial problems but not relocation. 
Certain personality traits might predispose people to experience stressful life events. Using data from four waves of the Australian Quality of Life Panel Study $(N=649)$ Headey and Wearing (1989) found stability in life events for adults. Over a 6-year period, life events were scored at three points. Correlations between favorable events' scores and correlations between adverse events' scores were both approximately 0.5 . In other words, both favorable and adverse events kept happening to the same people. In a 4-year prospective study of 136 collegeaged students, extraversion, as measured by the NEO Inventory, predisposed subjects to experience a greater number of objective positive events $(r=.24, p<.05)$ while a high score for neuroticism predisposed subjects to experience negative events $(r=.23, p<.05)$ (Magnus, Dienei, Fujita, \& Pavot, 1993).

Factors that are independent of the person undoubtedly influence life events. But personality may be a deciding element in a person's choice of situations that he or she will be exposed to. The relation of prior life events to behavior in dementia may be influenced by the type of personality an individual has.

\section{Life-span Perspective in Research}

Researchers have demonstrated linkages between behaviors in dementia and neuropathologic changes. While some symptoms of dementia arise from pathology, others may be generated and perpetuated by the environment and long-standing expressions of self. There is a need to develop an integrative theoretical approach to personality in dementia that balances knowledge of the biology of behavior, an understanding of the importance of the environment, and an appreciation of a person's life-long behavioral patterns (Rabins, 1994). A life-span perspective on personality would make an important contribution to the latter through retrospective accounts of premorbid personality and longitudinal studies that capture behavior processes over the course of the disease.

A number of measurement issues should be addressed if a lifespan perspective is to be effective. First, to capture the full range of behavior, broad-band scales are necessary (Patterson \& Bolger, 1994). Problematic behavior checklists are too narrow to describe and measure personality. They are useful for evaluation of subsets of behavior, such as hostility or aggression. But demented patients express both "positive" and "negative" behaviors, a fact we have been slow to recognize (Burgener, Shimer, \& Murrell, 1992).

A second issue in measurement is the need to go beyond reporting the frequency of specific behaviors to interpretation of their meaning. Understanding the purpose of behavior is the first step in developing effective interventions. Such understanding characterizes the uniqueness of the nursing perspective (Zadorozny \& Noelker, 1994). Appropriate sources of data include both patient self-reports, as well as the reports of close informants. Too often, demented patients are relegated to the status of object in research. In the early stages of the disease, the sense of "Who I am in the world" is not drastically altered (Sadavoy, 1991). At least one study has shown a high degree of reliability in self-reports of mild to moderately demented elders
(Richman, 1988). It seems that much useful data could be collected from the patient and would represent an accurate report of an individual's current experience of the disease (Cotrell \& Schulz, 1993).

Personality may also be reliably assessed through the report of close informants (Costa \& McCrae, 1988). Use of a variety of data sources is likely to provide a better indication of the meaning of behavior than any one single method alone.

Research is needed to determine why certain interventions are effective with different types of demented patients. It is likely that personality will be a variable; for instance, if a patient tends to be more open to experience, he or she may be receptive to change or novelty in routine and may actually benefit from it, at least in the early stages of dementia. On the other hand, a patient who has always been conservative and becomes more so with dementia-may respond best to stability and routine. As researchers compare outcomes for individuals with different personality profiles, the utility of unique interventions for different types of patients should become apparent.

\section{Life-span Perspective in Practice}

It has been said that it is not enough to know what kind of problem a patient has, we must know what kind of patient has the problem. Personality is a reliable predictor of adaptation or coping (Herbert \& Powell, 1989) and clinical observations have linked personality to the outcome of different types of therapy. Miller (1991) reports that patients who have both low neuroticism and high conscientious scores (NEO PI) respond well to psychotherapy. Additionally, those who rank high on openness, or extraversion, prefer active participation, while patients who rank low on openness are more amenable to directed forms of therapy. Knowledge of personality styles has been used to modify the treatment of older alcoholics (Hyer, Carson, \& Tamkin, 1987) and those with other psychogeriatric problems (Hyer \& Harrison, 1986).

Being able to identify the course of behavior that has been continuous throughout a patient's life may help caretakers understand and respond more appropriately to behaviors that seem aberrant. A good health history will encompass not only discreet facts that detail medical problems or patient preferences, but an interpretation of the meaning of behavior.

Images of the past can reduce anxiety and feelings of fragmentation. Sadavoy (1991) suggests that-by redirecting an anxious patient's attention to images of "evoked others" such as children, parents, or friends-caretakers can help an elder maintain self-cohesion. Helping a patient remember the past requires a detailed knowledge of the patient's history and the use of pictures, tapes, or other objects that are important to the patient.

In a life-span approach, behaviors that might ordinarily be perceived as difficult and in need of control can be interpreted in terms of past meanings and the current situation. An elderly woman who repeatedly asks to wash her hands, for example, may be expressing a life-long concern about being clean; a wanderer may be using activity as a way of reducing stress. As Cohen 
(1991) points out, if we do not know the patient's experience beyond the results of cognitive and functional tests, our interventions will not represent patient needs.

In interviews with cognitively impaired elders, Burgener, Shimer, and Murrell (1992) found a surprising amount of individual expressions of self. Elders, in their study, continually reacted in individual ways to what was happening and what they knew was expected of them. Strategies that support life-long personal characteristics and behavior affirm personal identity. Patients should be encouraged to express their wishes regarding care and the effect of care on their well-being (Cotrell \& Schulz, 1993). The trend toward earlier diagnosis provides an opportunity to solicit patient involvement in care decisions during the initial stages of disease. When language deficits limit verbal communication, biographical information about the individual's past may help fill the gap.

One instrument that can be used to identify behavioral patterns over time is the Behavioral Monitoring Log (Strumpf, Patterson, Evans, \& Wagner, 1992). The log was developed to describe the context of behavior in nursing-home residents and its parameters. Examination of patterns together with historical accounts provided by close informants using personality inventories such as the NEO may help caretakers identify the meaning of behavior.

Pietrukowicz and Johnson (1991) found that a life-span perspective improved the attitudes of caregivers toward residents. In their study, nurses' aides were given short-life histories of their patients perceived residents as more adaptable, goal-setting, and having more interactional skills after reviewing the life history than did aides in a control group. The authors reported that $95 \%$ of the aides wanted more historical information about their patients in order to know how to better care for them.

\section{Conclusion}

As a population ages, dementing illnesses can be expected to account for more morbidity and mortality. Dementing diseases rob people of their cognition. But the course of these illnesses is variable, and in early and mid-stages, vestiges of premorbid personality remain. Who people are over a lifetime may tell us much about who they are when they are ill. A life-span perspective is important to those who care for the demented because even in confusion and fragmentation there is a need to find and care for

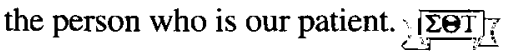

\section{References}

Allen, D. (1985). Nursing research and social control: Alternative models of science that emphasize understanding and emancipation. Image: Journal of Nursing Scholarship, 17, 58-64.

American Psychiatric Association (1994). Diagnostic and statistical manual of mental disorders, (4th ed.). Washington, DC: Author.

Atchley, R. (1989). A continuity theory of normal aging. The Gerontologist, 29(2), 183-190.

Benner, P., \& Wrubel, J. (1989). The privacy of caring: Stress and coping in health and illness. New York: Addison-Wesley.

Bozzola, F., Gorelick, P., \& Freels, S. (1992). Personality changes in Alzheimer's disease. Archives of Neurology, 49, 297-300.
Burgener, S., Jirovec, M., Murrell, L., \& Barton, D. (1992). Caregiver and environmental variables related to difficult behaviors in institutionalized demented elderly persons. Journal of Gerontology: Psychological Sciences, 47(4), 242-249.

Burgener, S., Shimer, R., \& Murrell, L. (1993). Expressions of individuality in cognitively impaired elders: Need for individual assessment and care. Journal of Gerontological Nursing, 19(4), 13-22.

Carey, G., \& DiLalla, D. (1994). Personality and psychopathology: Genetic perspectives. Journal of Abnormal Psychology, 103(1), 32-43.

Chatterjee, A., Strauss, M., Smyth, K., \& Whitehouse, P. (1992). Personality changes in Alzheimer's disease. Archives of Neurology, 49, 486-491.

Cohen, D. (1991). The subjective experience of Alzheimer's disease: The anatomy of an illness as perceived by patients and families. American Journal of Alzheimer's Care and Related Disorders \& Research, 6, 6-11.

Cohen-Mansfield, J., \& Marx, M. (1989). Do past experiences predict agitation in nursing home residents? International Journal of Human Development, 28(4), 285-294.

Cohen-Mansfield, J., \& Marx, M. (1992). The social network of the agitated nursing home resident. Research on Aging, 14(1), 110-123.

Cohen-Mansfield, J., Billig, N., Lipson, S., Rosenthal, A., \& Pawlson, L. (1990). Medical correlates of agitation in nursing home residents. Gerontology, 36, 150-158.

Colerick, E. J., \& George, L. K. (1986). Predictors of institutionalization among caregivers of patients with Alzheimer's disease. Journal of the American Geriatric Society, 34, 493-498.

Conley, J. (1984). Longitudinal consistency of adult personality: Self reported psychological characteristics across 45 years. Journal of Personality and Social Psychology, 47, 1325-1333.

Costa, P., \& McCrae, R. (1988). Personality in adulthood: A six-year longitudinal study of self-reports and spouse ratings on the NEO Personality Inventory. Journal of Personality and Social Psychology, 54(5), 853-863.

Costa, P., \& MeCrae, R. (1992). Revised NEO personality inventory and NEO five-factor inventory, professional manual. Odessa, FL: Psychological Assessment Resources.

Cotrell, V., \& Schulz, R. (1993). The perspective of the patient with Alzheimer's disease: A neglected dimension of dementia research. The Gerontologist, 33(2), 205-211.

deLeon, M., Portegal, M., \& Gurland, B. (1984). Wandering and parietal signs in senile dementia of Alzheimer's type. Neuropsychobiology, 11, 155-157.

Diamond, T. (1986). Social policy and everyday life in nursing homes: A critical ethnography. Social Science and Medicine, 23(12), 1287-1295.

Digman, J. (1990). Personality structure: Emergence of the five-factor model. Annual Review of Psychology, 41, 417-440.

Evans, L., Strumpf, N., Taylor, L., \& Jacobsen, B. (1990-92). Reducing restraints in nursing homes: A clinical trial. Grant No. 1, R01-(AG08324). Washington, DC: National Institute on Aging.

Field, D. (1991). Continuity and change in personality in old age-evidence from five longitudinal studies: Introduction to a special issue. Journal of Gerontology, 46(6), 271-274.

Field, D., \& Millsap, R. (1991). Personality in advanced old age: Continuity or change? Journal of Gerontology, 46(6), 299-308.

Glover, J. (1988). I: The philosophy and psychology of personal identity. London: Penguin Books.

Haan, N., Millsap, R., \& Hartka, E. (1986). As time goes by: Change and stability in personality over fifty years. Psychology and Aging, 1, 220-232.

Hamel, M., Pushkar, D., Andres, D., Reis, M., Dastoor, D., Grauer, H., \&

Bergman, H. (1990). Predictors and consequences of aggressive behavior by community-based dementia patients. The Gerontologist, 30(2), 206-211.

Headey, B., \& Wearing, A. (1989). Personality, life events, and subjective well -being: Toward a dynamic equilibrium model. Journal of Personality and Social Psychology, 57(4), 731-739.

Herbert, C., \& Powell, G. (1989). The role of personality factors in rehabilitation. Personality and Individual Differences, 10(9), 969-973.

Hyer, L., \& Harrison, W. (1986). Later life personality model diagnosis and treatment. In T. Brink (Ed.). Clinical gerontology: A guide to assessment and intervention (399-415). New York: The Haworth Press.

Hyer, L., Carson, M., \& Tamkin, A. (1987). Personality styles in the treatment of older alcoholics. Clinical Gerontologist, 7(2), 15-29.

Jenny, J., \& Logan, J. (1992). Knowing the patient: One aspect of clinical knowledge. Image: Journal of Nursing Scholarship, 24, 254-258. 
John, O., Angleitner, A., \& Ostendorf, F. (1988). The lexical approach to personality: A historical review of trait taxonomic research. European Journal of Personality, 2, 171-203.

Kahana, E. (1982). A congruence model of person-environment interaction. In M. P. Lawton, P. Windley, \& T. O. Byerts (Eds.), Aging and the environment: Theoretical approaches (97-121). New York: Springer.

Knesper, D., Giordani, B., Koeppe, R., \& Kuhl, D. (1994, June). Does cerebral metabolic asymmetry predict emotions? Poster session presented at the fifth annual Albert J. Silverman Research Conference, Ann Arbor, MI.

Lawton, M. P. (1982). Competence, environmental press, and the adaptation of older people. In M. Lawton, P. Windley, \& T. O. Byerts (Eds.), Aging and the environment: Theoretical approaches (33-59). New York: Springer.

Magnus, K., Dienei, E., Fujita, F., \& Pavot, W. (1993). Extraversion and neuroticism as predictors of objective life events: A longitudinal analysis. Journal of Personality and Social Psychology, 65(5), 1046-1053.

McCrae, R., \& Costa, P. (1987). Validation of the five-factor model of personality across instruments and observers. Journal of Personality and Social Psychology, 52, 877-883.

McCrae, R. (1989). Why I advocate the five-factor model: Joint analyses of the NEO-PI and other instruments. In D. Buss \& N. Cantor (Eds.), Personality psychology: Recent trends and emerging directions (237-245). New York: Springer-Verlag.

Meddaugh, D. (1994). Continuity theory: Just for normal aging? Unpublished manuscript.

Miller, T. (1991). The psychotherapeutic utility of the five-factor model of personality: A clinician's experience. Journal of Personality Assessment, 57(3), 415-433.

Milliard, P., \& Smith, C. (1981). Personal belongings-A positive effect? The Gerontologist, 21, 85-90.

Millon, T. (1969). Modern psychopathology. Philadelphia: Saunders.

Monsour, N., \& Robb, S. (1982). Wandering behavior in old age: A psychosocial study. Social Work, 27, 411-416.

Moos, R. (1980). Specialized living environment for older people. A conceptual framework for evaluation. Journal of Social Issues, 39(2), 75-94.

Neugarten, B. (1973). Personality change in late life: A developmental perspective. In C. Eisdorfer \& W. Lawton (Eds.). The Psychology of adult development and aging (311-335). Washington, DC: American Psychological Association.

Patterson, M., \& Bolger, J. (1994). Assessment of behavioral symptoms in Alzheimer's disease. Alzheimer's Disease and Associated Disorders, 8 (Suppl. 3), 4-20.

Petry, S., Cummings, J., Hill, M., \& Shapira, J. (1988). Personality alterations in dementia of the Alzheimer type. Archives of Neurology, 45, 1187-1190.

Pietrukowicz, M., \& Johnson, M. (1991). Using life histories to individualize nursing home staff attitudes toward residents. The Gerontologist, 31(1), 102106.

Rabins, P. (1994). The phenomenology of behavior: An overview of behavioral principles. Alzheimer's Disease and Associated Disorders, 8 (Suppl. 3), 6165.

Raskind, M., \& Peskind, E. (1994). Neurobiological bases of non-cognitive behavioral problems in Alzheimer's disease. Alzheimer's Disease and Associated Disorders, 8 (Suppl. 3), 54-60.

Richman, M. (1989). Stability of personality traits in the demented elderly (Doctoral dissertation, Hofstra University, 1989) Dissertation Abstracts International, 50, B 5367.

Rubin, E., Morris, J., \& Berg, L. (1987). The progression of personality changes in senile dementia of the Alzheimer's type. Journal of the American Geriatrics Society, 35, 721-725.

Ryden, M., Bossenmaier, \& McLachlan, C. (1991). Aggressive behavior in cognitively impaired nursing home residents. Research in Nursing and Health, 14, 87-95.

Sadavoy, J. (1991). Psychodynamic perspectives on Alzheimer's disease and related dementias. The American Journal of Alzheimer's Care and Related Disorders \& Research, 6(3), 12-20.

Shomaker, D. (1987). Problematic behavior and the Alzheimer patient: Retrospective as a method of understanding and counseling. The Gerontologist, 27(3), 370-375.

Siegler, I., Welsh, K., Dawson, D., Fillenbaum, G., Earl, N., Kaplan, E., \& Clark, C. (1991). Ratings of personality change in patients being evaluated for memory disorders. Alzheimer's Disease and Associated Disorders, 5(4) 240-250.
Snyder, L., Rupprecht, P., Pyrek, J., Brekhus, S., \& Moss, T. (1978) Wandering. The Gerontologist, 18(3), 272-280.

Strauss, M., Pasupathi, M., \& Chatterjee, A. (1993). Concordance between observers in descriptions of personality change in Alzheimer's disease. Psychology and Aging, 8(4), 475-480.

Strumpf, N., Patterson, J., Evans, L., \& Wagner, J. (1992). Reducing restraints: Individualized approaches to behavior. Huntingdon Valley, PA: The Whitman Group.

Sungaila, P., \& Crockett, D. (1993). Dementia and the frontal lobes. In R. Parks, R. Zec, \& R. Wilson (Eds.), Neuropsychology of Alzheimer's Disease and other dementias (235-264). New York: Oxford University Press.

Teri, L., Larson, E., \& Reiffer, B. (1988). Behavioral disturbance in dementia of the Alzheimer's type. Journal of the American Geriatrics Society, 36, 1-6.

Watson, D., Clark, L., \& Harkness, A. (1994). Structures of personality and their relevance to psychopathology. Journal of Abnormal Psychology, 103(1), 18 31.

Whall, A., Black, A. M., Yankou, D., \& Groh, C. (1994, September). Addressing aggressive behavior in demented nursing home residents. Paper presented at the Alzheimer's Disease Conference, Ann Arbor, MI.

Wolfer, J. (1993). Aspects of "reality" and ways of knowing in nursing: In search of an integrating paradigm. Image: Journal of Nursing Scholarship, 25, 141146

Wrightsman, L. (1988). Personality development in adulthood. Newbury Park, CA: Sage.

Zadorozny, C., \& Noelker, E. (1994). The uniqueness of the nursing perspective in managing behavioral problems. Alzheimer's Disease and Associated Disorders, 8 (Suppl. 3), 92-94.

Zuckerman, M. (1991). Psychobiology of personality. New York: Cambridge University Press. 